DOI: https://doi.org/10.47405/mjssh.v5i12.586

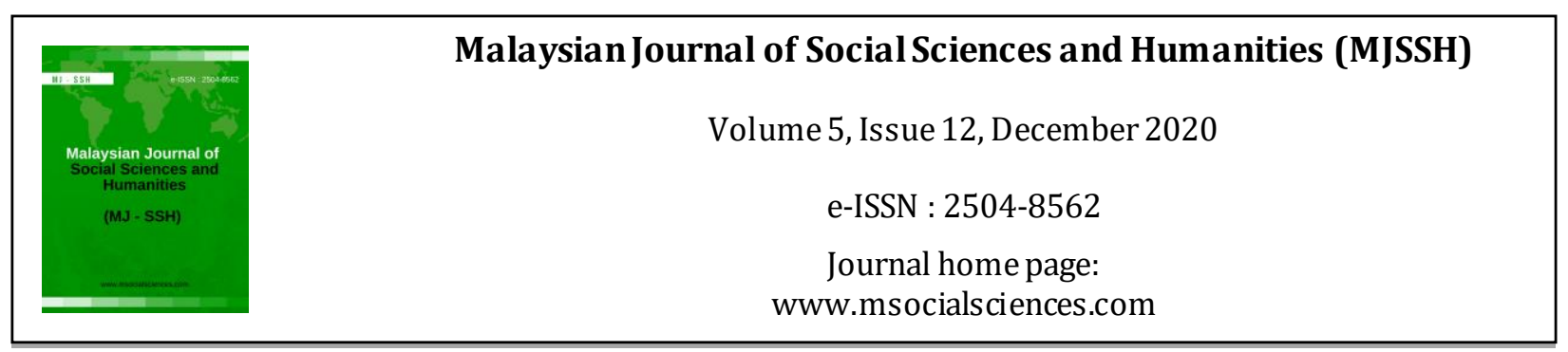

\title{
Reaksi Penduduk Sabah Terhadap Pembentukan Malaysia: Suatu Perbandingan Dulu dan Kini
}

\author{
Mohd Sohaimi Esa1, Romzi Ationg1 \\ ${ }^{1}$ Pusat Penataran Ilmu dan Bahasa, Universiti Malaysia Sabah (UMS) \\ Correspondence: Mohd Sohaimi Esa (msohaimi@ums.edu.my)
}

\begin{abstract}
Abstrak
Sejarah pembentukan Malaysia merupakan episod penting dalam konteks sejarah negara ini. Sekalipun Persekutuan Malaysia yang dibentuk pada asalnya adalah melibatkan Tanah Melayu, Sabah, Sarawak dan Singapura, tetapi artikel ini hanya akan memberi tumpuan ke-atas Sabah sahaja, khususnya dalam aspek reaksi penduduk di negeri ini terhadap pembentukan persekutuan tersebut dalam dua era yang berbeza iaitu sebelum dan selepas pembentukannya. Penelitian reaksi penduduk Sabah terhadap pembentukan Malaysia sebelum persekutuan adalah berasaskan penelitian terhadap data sekunder yang diperoleh dari akhbar tempatan yang diterbitkan pada ketika itu. Sebaliknya, bagi menilai reaksi penduduk Sabah selepas pembentukan Malaysia adalah berdasarkan penggunaan survei. Berdasarkan penggunaan kedua-dua kaedah tersebut maka adalah ditegaskan bahawa reaksi penduduk Sabah terhadap pembentukan Malaysia adalah pelbagai. Secara keseluruhannya dapatan tersebut memberi gambaran bahawa isu pembentukan Malaysia merupakan isu yang kekal hebat diperkatakan di negeri ini.
\end{abstract}

Kata Kunci: pembentukan Malaysia, Sabah, reaksi penduduk

\section{The Reaction of Sabah Peoples towards the Formation of Malaysia: Comparing the Past and Present}

\begin{abstract}
The formation of Malaysia has been an important episode in the history of this country. Though the Malaysian Federation originally included Malaya, Sabah, Sarawak dan Singapura, this paper focuses on Sabah only, particularly on reaction among Sabah people over the formation of Malaysia from two eras namely before and after the formation of Malaysia. Examination over Sabah peoples' reactions before the formation of Malaysia will be based on secondary data gathered from newspaper published during that era. In contrast, examination of Sabah peoples' reactions after the formation of Malaysia will be based on survey. Based on the application of both methods, this paper suggests that reactions among the people of Sabah over the formation of Malaysia were varied. Overall, it hinted that issue pertaining to the formation of Malaysia remains widely debated in Sabah up until today.
\end{abstract}

Keywords: Formation of Malaysia, Sabah, reaction of citizens 


\section{Pendahuluan}

Pada 27 Mei 1961, Tunku Abdul Rahman telah membuat pengumuman mengenai gagasan Malaysia yang merangkumi Tanah Melayu, Singapura dan tiga buah wilayah Borneo iaitu Sabah, Sarawak dan Brunei. Dalam konteks negeri Sabah (dikenali juga sebagai Borneo Utara ketika itu) telah menunjukkan reaksi serta merta apabila idea tersebut dikemukakan. Reaksi penduduk negeri ini dapat dilihat dalam kalangan pemimpin, mahupun rakyat jelata sebagaimana yang dapat digambarkan dalam akhbar tempatan (Ungku Maimunah, 1988; Ongkili, 1967; 1985, 1989; Clarence, 1981; Mohd. Sohaimi, 2001; 2009; Milne, 1963; Mat zin, Abdul Kadir, Jaafar \& Worran, 2011; Romzi, Azlan \& Andreas, 2018). Reaksi awal ini akan diteliti untuk melihat sejauh mana akhbar menjadi alat penting dalam mengurangkan salah faham berkaitan dengan gagasan Malaysia. Justeru itu, kajian secara kualitatif digunakan untuk melihat perkembangan reaksi tersebut pada awal gagasan ini diperkenalkan.

Sebagai perbandingan pula, penulis akan membincangkan reaksi penduduk Sabah dalam konteks kontemporari terhadap beberapa isu yang berkaitan dengan pembentukan Malaysia. Reaksi ini akan dilihat berdasarkan kajian survei di dua buah kawasan parlimen terpilih iaitu P170 Tuaran dan P174 Penampang. Antara isu yang dibangkitkan dalam kajian ini termasuklah Perjanjian Malaysia, Perkara 20 dan dokumen Inter-Government Committee (IGC) (Clark, 1974; Milne \& Mauzy, 1978; Herman, 1989, Granville-Edge, 1999; Vijay, 1998; Yamamoto, 1999; Mohd. Sohaimi, 2011). Pada dasarnya, beberapa isu tersebut menjadi penentu kepada hubungan kerajaan pusat dengan kerajaan negeri.

Walaupun disedari terdapat perbezaan yang ketara sekiranya untuk dibuat perbandingan, namun begitu terdapat beberapa ciri istimewa yang boleh diketengahkan jika ditinjau reaksi penduduk Sabah terhadap pembentukan Malaysia dulu dan kini. Antara ciri yang boleh diketengahkan termasuklah sejauh mana keprihatinan penduduk negeri ini terhadap isu yang membabitkan pembentukan Malaysia. Hal ini juga dapat memberikan gambaran sejauh mana pentingnya pembentukan Malaysia dalam kalangan orang Sabah. Seperkara lagi yang dapat diketengahkan ialah isu utama atau dominan yang sering diperkatakan oleh penduduk negeri ini sebelum dan selepas pembentukan Malaysia. Persoalannya, apakah isu-isu pembentukan Malaysia tersebut ada jalan penyelesaiannya? Sebelum dibincangkan perkara tersebut, maka terlebih dahulu dihuraikan reaksi awal penduduk Sabah terhadap pembentukan Malaysia berdasarkan akhbar-akhbar tempatan.

\section{Pembentukan Malaysia: Reaksi Awal Penduduk Sabah dalam konteks Akhbar Tempatan}

Di Sabah, akhbar utama yang menjadi lidah penyampai berkaitan dengan gagasan Malaysia ialah The North Borneo News and Sabah Times (NBNST). NBNST diterajui oleh Donald Stephens yang juga kemudiannya menjadi pemimpin utama negeri ini. Sebaik sahaja Tunku Abdul Rahman mengisytiharkan gagasan Malaysia pada 27 Mei 1961, akhbar tempatan Sabah telah menunjukkan reaksi serta merta, termasuklah antaranya NBNST. NBNST telah menyiarkan berita tersebut pada 29 Mei dengan dipilih sebagai tajuk utama di muka hadapan akhbar ini, "Tengku's Big Unity Plan: Closer Ties Among British Borneo, Singapore and Malaya” (NBNST, 29 Mei 1961). Di sini dapat ditafsirkan bahawa betapa pentingnya berita ini kepada penduduk Sabah, walaupun beritanya hanya dipetik dari akhbar The Sunday Times (The Sunday Times, 28 Mei 1961).

Secara ringkasnya, isu-isu yang diutarakan oleh NBNST ialah Sabah sebagai salah sebuah negeri yang dicadangkan menjadi anggota Persekutuan Malaysia, masalah komunis, isu orang Cina, kedudukan bahasa Melayu dan pendidikan, kerjasama politik dan ekonomi. Tarikh keramat ini menandakan sebagai titik terawal berita yang disampaikan oleh akhbar berkenaan kepada penduduk negeri ini berkaitan dengan idea pembentukan Malaysia. Sejak itu, rancangan penubuhan Persekutuan Malaysia merupakan topik utama yang dibincangkan oleh penduduk negeri Sabah.

Sebagai akhbar utama di Sabah, NBNST telah menyiarkan berita serta memberikan ulasan terhadap reaksi penduduk negeri ini terhadap gagasan Malaysia. Sebagai contoh, menerusi editornya, Donald Stephens dalam ruangan, 'Random Thoughts Roderick' pada 31 Mei 1961, beliau telah memberikan 
reaksi positif terhadap idea Tunku Abdul Rahman, "We welcome Tunku Abdul Rahman's suggestion that Malaya, Singapore and the Borneo Territories should get closer together..." (NBNST, 31 Mei 1961). Walau bagaimanapun, beliau mencadangkan agar sebelum idea Tunku Abdul Rahman dilaksanakan maka hendaklah dilakukan sebagaimana berikut:

"The Borneo Territories must first get together... All these will take time and patience. As a first step let us work out the closer association of the Borneo Territories and as a first step Malaya and Singapore should also work out a merger - and then we can really get down to work on getting a Confederation of the Commonwealth Countries of Southeast Asia" (NBNST, 31 Mei 1961).

Pada 6 Julai 1961, NBNST telah menyiarkan pula berita Tunku Abdul Rahman yang diwawancara oleh pemberita dari Brunei memaklumkan bahawa Persekutuan Borneo sebagai negeri ke-12, 13 dan 14 di dalam Persekutuan Malaysia. Selang dua hari kemudian, sekali lagi berita disiarkan untuk perkara yang sama tentang pendirian Tunku tersebut sewaktu beliau membuat sidang akhbar di Sibu, Sarawak. Dengan kata lain, Sabah, Sarawak dan Brunei adalah sama kedudukan dan kekuasaannya sebagaimana negeri-negeri yang terdapat di Tanah Melayu. Tambahan pula, idea ini sudah pasti bertentangan dengan kehendak awal mereka agar Persekutuan Borneo diwujudkan terlebih dahulu, barulah dibincangkan untuk dibentuk gabungan dengan Tanah Melayu (Means, 1970). Liputan ini telah menimbulkan reaksi kurang senang penduduk Sabah terhadap rancangan pembentukan Malaysia.

Susulan itu, dalam ruangan editorial akhbar NBNST dengan tajuk, An Open Letter to Tengku Abdul Rahman, Donald Stephens dengan tegas menentang cadangan Tunku Abdul Rahman tersebut:

"Malaya s proposal that we should join as the 12th, 13th and 14th State savors of "imperialism", of desire by Malaya to turn us into Malayan Colonies. We too have our pride dear Tengku, and even though we are only Colonies it is natural that we should want to obtain our own independence: to join Malaya while we are still colonies can only mean one thing - that we would merely cease to be British Colonies and become Malayan colonies instead" (NBNST, 7 Julai 1961; Romzi, 2017).

Reaksi Donald Stephens tersebut telah menarik minat pembaca akhbar NBNST yang turut sama memberikan pandangan masing-masing. Namun begitu, ada antara mereka yang merasakan perlunya juga gagasan tersebut diterima secara positif untuk kepentingan negeri ini. Antara lain alasan mereka ialah Sabah mempunyai ciri-ciri budaya dan sejarah politik yang hampir sama dengan Tanah Melayu (Mohd. Sohaimi, Romzi, Suraya, Abang, Mohd Azri \& Sirahim, 2020; Ismail, 1997; Andaya \& Andaya, 1982). Susulan itu, Donald Stephens telah membuat ulasan kepada soalan yang diterima daripada salah seorang pembaca akhbarnya menerusi halaman bahasa Melayu dengan menulis bahawa "Rancangan Tunku Abdul Rahman:

"Malaysia' sangat tergesa-gesa dan kelamkabut, sedangkan Malaya baru
menchapai kemerdekaan belum lebeh dari 4 tahun dan banyak lagi perkara
didalam Malaya sendiri yang belum dapat diselesaikan. Jika Sabah ini terlepas
dari Colony Malaya, boleh jadi kita ini sebagai kata pepatah Terlepas dari mulut
harimau masok pula kemulut buaya" (NBNST, 17 Julai 1971).

Selain dari editor NBNST, akhbar ini juga menyiarkan kekecewaan terhadap pandangan Tunku Abdul Rahman tersebut dengan memetik dalam ruangan editorial sebuah akhbar Cina tempatan, Api Slang Pau iaitu dengan tegasnya, "We deeply believe that the majority of the people in this country will not like to see Sabah become a State of the Federation of Malaya" (NBNST, 8 Julai 1961). Nyatalah ulasan yang diberikan terhadap idea Tunku Abdul Rahman tersebut adalah selari bagi kedua-dua akhbar berkenaan dan tentunya memberi kesan ke atas pembaca yang terdiri daripada pelbagai lapisan masyarakat.

NBNST turut memetik dari akhbar berbahasa Cina, Borneo Times yang diterbitkan di Sandakan yang melaporkan rasa tidak puas hati terhadap idea Tunku Abdul Rahman tersebut. Rasa tidak puas hati ini 
dikemukakan oleh para pemimpin Cina dan beberapa buah pertubuhan di Sandakan seperti Chinese Chamber of Commerce, Teo Chiew Association, Fishermen's Association dan Hockkien Association. Mereka menganggap idea tersebut sebagai “Tengku's Aggressive Plan”, yakni sesuai dengan langkah Tanah Melayu untuk menjajah negeri ini” (NBNST, 19 Julai 1961).

Masalah utama untuk menyatakan pendirian penduduk Sabah ke atas penubuhan Malaysia lahir akibat tidak ada lagi parti politik yang ditubuhkan ketika itu. Justeru itu, NBNST menerusi ruangan 'Editorial' berusaha untuk memberikan kesedaran dan memupuk semangat nasionalisme dalam kalangan rakyat agar bersatu-padu serta mencadangkan agar ditubuhkan sebuah parti politik sebagaimana pernyataan bahawa "the only way to do it with any force is to say it together and that can best be done by political party which shall comprise of all the races living in this country" (NBNST, 19 Julai 1961).

Donald Stephens juga turut mencadangkan agar dibentuk satu parti perikatan sebagaimana yang terdapat di Tanah Melayu (gabungan UMNO, MCA dan MIC). Perbezaan di antara kedua-dua parti ini terletak pada keahliannya iaitu ahli hendaklah atas nama parti perikatan bukan sebagai ahli parti politik mengikut kaum masing-masing seperti yang terdapat di Tanah Melayu. Pandangan ini berlandaskan kepada keperluan semangat bersatu padu tanpa mengira kaum dalam usaha memperjuangkan kemerdekaan negeri ini sebagaimana berikut:

“we” here means all of us, Kadazan, Bajaus, Malays, Muruts, Chinese, Europeans, Kadayans, Indians all who acknowledge this land as our home and the first object of our loyalty, the only way to do it with any force is to say it together and that can best be done by a political party which shall comprise of all the races living in this country" (NBNST, 19 Julai 1961).

Susulan itu, beberapa buah parti politik mula ditubuhkan bermula dengan United National Kadazan Organization (UNKO) pada Ogos 1961. UNKO diasaskan oleh Donald Stephens yang sememang namanya tidak asing lagi dalam akhbar NBNST. Pada Disember 1961, United Sabah National Organization (USNO) pula ditubuhkan dengan diasaskan oleh Datu Mustapha Datu Harun (Romzi, Mohd. Sohaimi \& Mohd. Azri, 2020; Romzi, Mohd Azri, Mohd. Sohaimi \& Madiyem, 2020). Sesungguhnya dengan kelahiran kedua-dua parti ini semakin mengukuhkan lagi suara penduduk Sabah dalam usaha merealisasikan pembentukan Malaysia.

Selain itu, akhbar NBNST dalam usaha untuk mendapat reaksi daripada para pembaca telah membuka satu ruangan khas yang dikenali sebagai "Saturday Forum". Ruangan khas ini adalah untuk membincangkan reaksi mereka terhadap penubuhan Malaysia sama ada mereka bersetuju atau sebaliknya, serta perbincangan berkaitan dengan "safeguard" negeri ini. Sementara bagi mereka yang tidak bersetuju terhadap gagasan inii diberi jaminan sebagaimana berikut:

"Angry or abusive, destructive letter will not be publised, but each letter will receive the personal attention of the editor and the writer will receive a reply" (NBNST, 14 Oktober 1961).

Jelaslah bahawa pembentukan Malaysia merupakan isu yang sangat penting bagi penduduk negeri Sabah. Mereka mengambil berat akan masa depan negeri ini sekiranya berada dalam Persekutuan Malaysia. Hal ini jelas digambarkan pada awal pembentukan Malaysia sepertimana yang dilaporkan oleh akhbar tempatan, khususnya NBNST. Persoalannya, bagaimanakah pula reaksi penduduk Sabah selepas pembentukan Malaysia pada masa kini?

\section{Pembentukan Malaysia: Reaksi Penduduk Sabah Pada Masa Kini}

Pada 16 September 1963, Sabah bersama-sama dengan Singapura dan Sarawak telah mencapai kemerdekaan dalam Persekutuan Malaysia. Antara perkara penting berkaitan dengan pembentukan Malaysia termasuklah Perkara 20 Sabah, Dokumen Inter-Government Committee (IGC) dan Perjanjian Malaysia (Malaysia Agreement) 1963. Ketiga-tiga perkara tersebut sering menjadi isu yang masih terus 
dibangkitkan dan diperkatakan oleh penduduk negeri ini sungguhpun lebih dari setengah abad merdeka. Justeru itu, kajian ini dijalankan secara kualitatif dengan mengedarkan borang soal selidik. Borang soal selidik ini mengandungi beberapa isu yang berkaitan dengan pembentukan Malaysia. Hal ini dapat dikaitkan dengan sentimen kenegerian, serta membabitkan hubungan antara kerajaan negeri dengan kerajaan pusat.

Kajian reaksi penduduk Sabah ini dijalankan di dua kawasan parlimen terpilih iaitu P170 Tuaran dan P174 Penampang. P170 Tuaran dipilih kerana kedudukan parlimen ini dikuasai oleh Barisan Nasional (BN), sementara P174 Penampang pula dikuasai oleh Parti Keadilan Rakyat (PKR) semasa PRU 2013. Kawasan Parlimen P170 Tuaran terletak di Zon Pantai Barat Selatan. Daerah ini terdiri daripada tiga kawasan Undangan Negeri iaitu N9 Tamparuli, N10 Sulaman dan N11 Kuilu. Kawasan parlimen P174 Penampang pula merupakan sebuah kerusi kawasan separa bandar (semi-urban) yang terletak dalam Zon Pantai Barat Selatan. Terdapat dua kawasan Dewan Undangan Negeri (DUN) yang terangkum dalam kawasan parlimen ini, yakni N19 Kapayan dan N20 Moyog. Sesungguhnya, dengan wujudnya perbezaan politik tersebut, pemilihan kedua-dua kawasan ini akan dapat melihat lebih objektif berkaitan dengan reaksi mereka terhadap isu-isu pembentukan Malaysia. Penyelidikan ini dijalankan pada bulan Februari hingga April 2015. Skala reaksi yang digunakan adalah sepertimana berikut: Tidak Setuju (1), Kurang Setuju (2), Sederhana Setuju (3), Setuju (4), Sangat Setuju (5), Tidak Tahu (6) dan Tidak Menjawab (7). Berdasarkan kepada kajian di lapangan yang telah dijalankan, Jadual 1 di bawah adalah menunjukkan reaksi penduduk di Tuaran berkaitan dengan isu-isu pembentukan Malaysia.

Jadual 1: Reaksi Penduduk P170 Tuaran berkaitan dengan

Isu-isu Pembentukan Malaysia $(\mathrm{N}=748)$

\begin{tabular}{|c|c|c|c|c|c|c|c|c|}
\hline Bil & Perkara & 1 & 2 & 3 & 4 & 5 & $0(6)$ & $\mathbf{X}(7)$ \\
\hline \multirow{3}{*}{1} & $\begin{array}{l}\text { Perkara di bawah penting dalam konteks hubungan } \\
\text { kerajaan persekutuan dan negeri: } \\
\text { - } 20 \text { Point }\end{array}$ & 1.5 & 3.7 & 25.1 & 16.4 & 49.1 & 1.5 & 2.7 \\
\hline & $\begin{array}{l}\text { Dokumen Inter-Governmental } \\
\text { Committee (IGC) }\end{array}$ & 2.4 & 7.1 & 26.5 & 16.7 & 41.7 & 1.6 & 4.0 \\
\hline & $\begin{array}{l}\text { Perjanjian Malaysia (Malaysia } \\
\text { Agreement) } 1963\end{array}$ & 0.9 & 4.1 & 21.9 & 17.0 & 51.6 & 1.6 & 2.8 \\
\hline 2 & Perjanjian Malaysia 1963 patut disemak-semula. & 2.3 & 4.5 & 16.0 & 17.1 & 56.1 & 1.2 & 2.7 \\
\hline 3 & $\begin{array}{l}\text { Agihan 5\% royalti minyak untuk Sabah adalah } \\
\text { munasabah. }\end{array}$ & 52.5 & 16.7 & 18.9 & 6.3 & 4.9 & 0.3 & 0.4 \\
\hline 4 & Kempen SSKM adalah munasabah. & 0.6 & 14.2 & 40.2 & 15.4 & 14.8 & 0.9 & 3.9 \\
\hline 5 & $\begin{array}{l}\text { Perbezaan harga barangan di Sabah/Sarawak } \\
\text { berbanding Semenanjung Malaysia adalah } \\
\text { munasabah. (Dasar kabotaj). }\end{array}$ & 53.3 & 18.2 & 15.6 & 7.8 & 3.7 & 0.7 & 0.7 \\
\hline
\end{tabular}

Sumber: Lai et al. (2016)

Berdasarkan Jadual 1 di atas, terdapat beberapa isu yang menjadi perhatian para responden berkaitan dengan isu-isu pembentukan Malaysia. Pada umumnya, majoriti responden mementingkan perkaraperkara dalam konteks hubungan persekutuan-negeri terutamanya Perkara 20 (65.5\%) dan IGC (58.4\%) serta Perjanjian Malaysia 1963 (68.6\%). Perkara ini antara lain disebabkan masyarakat terdedah kepada isu-isu berkenaan yang selalu terpapar di media massa, terutamanya di aplikasi Facebook dan WhatsApp. Disebabkan para responden mula sedar dan terdedah akan perkara ini, majoriti responden iaitu sebanyak 73.2\% bersetuju agar Perjanjian Malaysia 1963 perlu disemak semula. Walau bagaimanapun, responden berbelah bagi iaitu sebanyak 40.2\% terhadap kempen SKMM. Bagi mereka kempen SKMM tidak relevan asalkan kerajaan Persekutuan masih mengambil perhatian terhadap pembangunan negeri Sabah. Mengenai isu royalti minyak, responden tidak bersetuju iaitu sebanyak $69.2 \%$ terhadap pemberian hanya sebanyak lima peratus sahaja kepada negeri ini. Perkara ini antara lain disebabkan responden mula sedar bahawa Sabah merupakan antara pengeluar minyak terbesar di Malaysia. Responden juga tidak bersetuju iaitu sebanyak 71.5\% terhadap Dasar Kabotaj yang dilihat tidak adil kepada masyarakat Sabah. Rumusannya, majoriti penduduk Tuaran mahu agar pihak kerajaan mengambil perhatian terhadap isu-isu yang ada kaitan dengan pembentukan Malaysia. Hal ini termasuklah berkaitan dengan isu harga barang dan royalti minyak.

Bagi mendapatkan perbandingan dan reaksi penduduk yang berbeza kawasan Parlimen, Jadual 2 di bawah secara jelas menunjukkan reaksi penduduk di Penampang berkaitan dengan isu-isu yang sama sepertimana di parlimen Tuaran. 
DOI: https://doi.org/10.47405/mjssh.v5i12.586

Jadual 2: Reaksi penduduk P 174 Penampang berkaitan dengan

Isu-isu Pembentukan Malaysia ( $\mathrm{N}=500)$

\begin{tabular}{|c|c|c|c|c|c|c|c|c|}
\hline Bil & Perkara & 1 & 2 & 3 & 4 & 5 & 0(6) & $x(7)$ \\
\hline \multirow{3}{*}{1} & $\begin{array}{l}\text { Perkara di bawah penting dalam konteks hubungan } \\
\text { kerajaan persekutuan dan negeri: } \\
\text { - } 20 \text { Point }\end{array}$ & 4.4 & 6.0 & 37.6 & 21.4 & 30.6 & 0 & 0 \\
\hline & (IGC) Dokumen Inter-Governmental Committee & 1.2 & 10.0 & 45.6 & 18.8 & 24.4 & 0 & 0 \\
\hline & $\begin{array}{l}\text { Perjanjian Malaysia (Malaysia } \\
\text { Agreement) } 1963\end{array}$ & 2.4 & 8.4 & 39.8 & 21.0 & 28.4 & 0 & 0 \\
\hline 2 & Perjanjian Malaysia 1963 patut disemak-semula. & 2.0 & 5.0 & 19.0 & 22.6 & 51.4 & 0 & 0 \\
\hline 3 & $\begin{array}{l}\text { Agihan } 5 \% \text { royalti minyak untuk Sabah adalah } \\
\text { munasabah. }\end{array}$ & 48.4 & 18.6 & 23.6 & 5.6 & 3.8 & 0 & 0 \\
\hline 4 & Kempen SSKM adalah munasabah. & 14.8 & 15.6 & 37.0 & 17.6 & 15.0 & 0 & 0 \\
\hline 5 & $\begin{array}{l}\text { Perbezaan harga barangan di Sabah/Sarawak } \\
\text { berbanding Semenanjung Malaysia adalah } \\
\text { munasabah. (Dasar kabotaj). }\end{array}$ & 33.8 & 31.2 & 23.6 & 7.6 & 3.8 & 0 & 0 \\
\hline
\end{tabular}

Sumber: Lai et al. (2016)

Berdasarkan Jadual 2, kajian mendapati bahawa 52\% daripada responden di Penampang berpendapat secara affirmative (sangat setuju/setuju) bahawa Perkara 20 adalah penting dalam konteks hubungan kerajaan persekutuan-negeri, manakala hanya lebih kurang $10 \%$ sahaja yang berpandangan sebaliknya. Walau bagaimanapun, untuk dua sub-item Dokumen IGC dan Perjanjian Malaysia 1963, respons didapati kurang affirmative berbanding dengan Perkara 20, dengan $45.6 \%$ dan $39.8 \%$ responden menjawab sederhana setuju. Trend ini mungkin disebabkan oleh keterlihatan (visibility) serta kesedaran yang lebih tinggi terhadap Perkara 20 berbanding dengan dua buah dokumen penubuhan Malaysia yang lain itu.

Walaupun begitu, seramai $74 \%$ tetap berpandangan secara affirmative (setuju/sangat setuju) bahawa Perjanjian Malaysia 1963 (MA63) perlu disemak semula. Begitu juga dengan ketidakpuasan hati 67\% responden terhadap kadar royalti minyak. Trend yang sama turut direkodkan untuk persoalan kesan dasar kabotaj kerana 65\% menolak pernyataan bahawa perbezaan harga barangan antara Semenanjung dan Sabah adalah munasabah. Sungguhpun sentimen kenegerian dan ketidakpuasan hati terhadap status hubungan Persekutuan-Negeri amat menonjol, pendapat para responden di Penampang didapati berbelah bahagi dan kurang affirmative berkaitan dengan pergerakan SSKM mahupun pendirian mereka terhadap agenda "pemisahan" yang diperjuangkan oleh pertubuhan sedemikian. .

\section{Kesimpulan}

Berdasarkan perbincangan, reaksi penduduk Sabah terhadap pembentukan Malaysia antara dulu dan kini terdapat elemen yang konsisten. Hal ini dapat dilihat dalam kalangan pemimpin, mahupun rakyat jelata. Pada hakikatnya, isu-isu berkaitan dengan pembentukan Malaysia sangat penting dan dekat di hati penduduk Sabah. Jika dulu reaksi ini dapat dilihat berdasarkan laporan akhbar yang diterbitkan ketika itu. Namun kini isu-isu ini boleh dilihat dan dikaji berdasarkan kajian di lapangan. Seperkara lagi yang penting dapat dilihat ialah keprihatinan penduduk Sabah terhadap 'safeguard' penduduk negeri ini sejak sebelum, mahupun selepas Sabah dalam Malaysia sehingga kini. Hal ini dapat dikaitkan dengan sentimen kenegerian, serta hubungan antara kerajaan negeri dengan kerajaan Persekutuan. Secara keseluruhannya, walaupun terdapat elemen kurang puas hati, penduduk Sabah berpendapat perlunya negeri ini sebagai sebahagian dari Malaysia. Namun begitu, mereka mahu hak dan "safeguard" negeri ini diberikan keutamaan sepertimana yang termaktub semasa Perjanjian Malaysia pada tahun 1963. Jelasnya, isu-isu berkaitan dengan pembentukan Malaysia belum ada titik nota kerana terus dibicarakan dan diperdebatkan sehingga kini. Hal ini berlaku antara lain dapat dikaitkan dengan isu-isu pembangunan dan bidang kuasa negeri yang masih wujud perasaan tidak puas hati dalam kalangan penduduk negeri ini. 


\section{Penghargaan}

Kertas kerja ini telah dibentangkan dalam 'Majlis Polemik Sejarah Malaysia Sesi ke-39, Arkib Negara Malaysia, Kuala Lumpur, 14 November 2017'.

\section{Rujukan}

Andaya, B.W. \& Andaya, L.Y. (1982). A History of Malaysia. London: Macmillan Press Ltd.

Clarence, D.B.M. (1981). Political Development in Sabah: 1881-1981. Dlm. Anwar Sullivan \& Cecilia Leong (ed.), Commemorative History of Sabah: 1881-1981. Kota Kinabalu, Sabah: Sabah State Government.

Clark, R.M. (1974). The Politics of Belonging: Political changes in Sabah and Sarawak. Kuala Lumpur: Oxford University Press.

Granville-Edge, P.J. (1999). The Sabahan: The Life and Death of Tun Fuad Stephens. Kuala Lumpur: Caxton Printing Sdn. Bhd.

Herman Luping (1989). Formation of Malaysia Revisted. Dlm. dalam Jeffrey G. Kitingan \& Maximus J. Ongkili, (ed.), Sabah 25 Years Later; 1963-1988. Kota Kinabalu, Sabah: Institute for Development Studies (Sabah).

Ismail Yusoff (1997). Politik dan Agama di Sabah. Bangi: Penerbit Universiti Kebangsaan Malaysia.

Lai Yew Meng, Paul, Mohd. Sohaimi, Haijon, Anantha Raman, Carlevin, Mohd Rahezzal, Tony, Arnold, \& Mohd. Azri (2016). Laporan Kajian Elektoral Malaysia di Sabah (Laporan Teknikal). Kuala Lumpur: Majlis Profesor Negara

Mat Zin Mat Kib, Abdul Kadir Rosline, Jasman Jaafar \& Worran Kabu. (2011). Pembentukan Malaysia: Suatu Sorotan dalam Akhbar North Borneo News and Sabah Times. Dlm. Mat Zin Mat Kib, Abdul Kadir Rosline, Jasman Jaafar \& Worran Kabul. (eds.), Pembentukan Malaysia: Isu dan Perdebatan. Shah Alam, Selangor: Penerbit UiTM.

Means, G.P. (1970). Malaysian Politics. London, UK: Hodder and Stoughton.

Milne, R.S. \& Mauzy, D.K. (1978). Politics and Government in Malaysia. Singapore: Federal Publications.

Milne, R.S. (1963). Malaysia: A New Federation in the Making. Asian Survey, Februari.

Mohd Sohaimi Esa (2001). Reaksi Awal Penduduk Borneo Utara ke atas Penubuhan Malaysia dalam laporan akhbar The North Borneo News and Sabah Times (Mei-Disember 1961). MANU, 6.

Mohd Sohaimi Esa (2009). Kelahiran Parti Politik di Sabah: Kajian Akhbar Tempatan (1961-1962). MANU, 15.

Mohd. Sohaimi Esa (2011). Sumbangan Tun Abdul Razak dalam membina hubungan MalaysiaIndonesia. Journal Jabatan Sejarah Universiti Malaya, 11, 397-216

Mohd. Sohaimi Esa, Romzi Ationg, Suraya Sintang, Abang Mohd. Razif Abang Muiz, Mohd Azri Ibrahim \& Sirahim Abdullah (2020). Youth Voluntary Organization, Leadership and Intergroup Relationship in Sabah, Malaysia: A Preliminary Discussion. Solid State Technology, 63(6), 722730.

NBNST - North Borneo News and Sabah Times, Mei - Disember 1961.

Ongkili, J.P. (1967). The Borneo Response to Malaysia: 1961-1963. Singapore: Donald Moore Press Ltd.

Ongkili, J.P. (1989). Political Development in Sabah, 1963-1988. Dlm. dalam Jeffrey Kitingan \& Maximus J. Ongkili (eds.), Sabab 25 Years Later; 1963-1988. Kota Kinabalu, Sabah: Institute for Development Studies (Sabah).

Ongklli, J.P. (1985). Nation Building in Malaya: 1946-1974. Singapore: Oxford University Press.

Romzi Ationg (2017). Federal Political Elites and the Expansion of Ethnic Politics to the Periphery State of Sabah in Malaysia. The Australian National University, Canberra, Australia.

Romzi Ationg, Azlan Gansau \& Andreas Totu. (2018). Ethnohistorical Analysis on the Resurgence of Multiracial Political Ideology through 'Sabah for Sabahan 'Slogan in Sabah, Malaysia. ASEAN/Asian Academic Society International Conference Proceeding Series, 186-194.

Romzi Ationg, Mohd Azri Ibrahim, Mohd. Sohaimi Esa \& Madiyem Layapan (2020). Analisis Pola Pengundian dan Senario Politik Semasa di Malaysia Era Pasca Pilihan Raya Umum (PRU) Ke-14 
Berdasarkan Pilihan Raya Kecil P186 Sandakan, Sabah. Malaysian Journal of Social Sciences and Humanities (MJSSH), 5(5), 60-71.

Romzi Ationg, Mohd. Sohaimi Esa \& Mohd. Azri Ibrahim (2020). Menyingkap Polemik Peralihan Kuasa Secara Luar Biasa Mengikut Perspektif Demokrasi Berparlimen. Malaysian Journal of Social Sciences and Humanities (MJSSH), 5(11), 43-53.

The Sunday Times, Mei 1961.

Ungku Maimunah Mohd. Tahir (1988). North Borneo News and Sabak Times Sebagai Wadah Sastera Melayu Moden di Sabah Sebelum Merdeka (1954-1963). Dlm. Mohd. Sarim Haji Mustajab (ed.), Akhbar dan Majalah di Malaysia. Jabatan Sejarah, Universiti Kebangsaan Malaysia.

Vejai Balasubramaniam (1998). Politik Nasionalisme dan Federalisme di Malaysia. Shah Alam: Penerbit Fajar Bakti.

Yamamoto Hiroyuki (1999). From Bornean Federation to Malaysia, Analysis of 'Stephens' Plan for 'Merdeka. MANU, 2. 